\title{
Corrosion Protection Properties Afforded by an In Situ Electropolymerized Polypyrrole Layer on CuZn
}

\author{
Anna M. Fenelon* and Carmel B. Breslin**,z \\ Department of Chemistry, National University of Ireland, Maynooth, Maynooth, County Kildare, Ireland
}

\begin{abstract}
Adherent polypyrrole films were electropolymerized from a near-neutral sodium oxalate solution at a CuZn electrode. The growth of these films was facilitated by the initial oxidation of the CuZn electrode in the oxalate solution to generate a zinc-containing copper(II) oxalate pseudopassive layer. This layer was sufficiently protective to inhibit further dissolution of the CuZn electrode and sufficiently conductive to enable the electropolymerization of pyrrole at the interface, and the generation of an adherent polypyrrole film. These films exhibited significant corrosion protection properties in acidified and neutral $0.1 \mathrm{~mol} \mathrm{dm}^{-3} \mathrm{NaCl}$ solutions. On continued immersion in these solutions, the polymer films lost some of their corrosion-protection properties, but still remained stable, offering good corrosion protection to the CuZn substrate.
\end{abstract}

(C) 2003 The Electrochemical Society. [DOI: 10.1149/1.1618225] All rights reserved.

Manuscript submitted June 13, 2002; revised manuscript received May 18, 2003. Available electronically September $25,2003$.

There is much interest in the corrosion reactions of $\mathrm{Cu}-\mathrm{Zn}$ electrodes (brass) and in the development of inhibitors or inhibitor-based coatings suitable for protecting $\mathrm{Cu}-\mathrm{Zn}$ systems from corroding. Many of the corrosion protection strategies center on the inhibitors employed in the corrosion protection of pure copper. For example, the well-known benzotriazole species, which is an excellent corrosion inhibitor for pure copper, has been used to inhibit the corrosion of $\mathrm{Cu}-\mathrm{Zn}{ }^{1-6}$ It has been reported that benzotriazole inhibits the stress corrosion cracking of $\mathrm{Cu}-30 \mathrm{Zn}$ in fluoride solutions ${ }^{1}$ and $\mathrm{Cu}-$ 28Zn in nitrite solutions. ${ }^{2}$ Chadwick and Hashemi ${ }^{3}$ have detected both copper and zinc in surface films formed on $\mathrm{Cu}-30 \mathrm{Zn}$ in chloride-containing benzotriazole solutions, Gupta et al., ${ }^{4}$ reported that benzotriazole inhibited corrosion of the copper component, but had little effect on the rate of dezincification of a Cu-30Zn electrode, while Costa et al. ${ }^{5}$ suggested that the film formed on $\mathrm{Cu}-30 \mathrm{Zn}$ in $\mathrm{H}_{2} \mathrm{SO}_{4}$-containing benzotriazole solutions consisted of polymeric $\mathrm{Cu}(\mathrm{I})$-benzotriazole units.

Triazole derivatives have also been evaluated as corrosion inhibitors for CuZn. Quraishi et al. ${ }^{7}$ have reported the inhibition of dezincification of 70-30 brass by aminoalkyl mercaptotriazoles, while 3-amino-5-heptyl-1,2,4,-triazole has been used as an anodic inhibitor. ${ }^{8}$ Benzimidazoles and substituted benzimidazoles have also been used in the corrosion protection of CuZn. ${ }^{9,10}$

Although conducting polymers have been used extensively in the corrosion protection of iron and iron-based alloys, ${ }^{11-14}$ there are, to the best of our knowledge, no reports devoted to the corrosion protection properties of these polymers when applied to copper-zinc alloys. Second, there are no reports in the literature on the electropolymerization of appropriate monomers to generate conducting polymers at a CuZn electrode. Although it is relatively easy to spin-coat conducting polymers at any surface, it is much more difficult to deposit the conducting polymers using in situ electropolymerization conditions, as in many cases the metal will dissolve before the electropolymerization potential of the monomer is reached. However, the electropolymerization approach offers several advantages over other coating technologies, such as spin coating; the main advantage being the ability to form the polymer on irregular-shaped objects.

In this paper, results are presented on the in situ electropolymerization of pyrrole at a copper-zinc electrode from a near-neutral oxalate solution to produce a smooth and adherent polypyrrole coating. The corrosion protection properties of this layer are assessed using electrochemical techniques in highly aggressive chloridecontaining solutions.

\footnotetext{
* Electrochemical Society Student Member.

** Electrochemical Society Active Member.

${ }^{\mathrm{z}}$ E-mail: cb.breslin@may.ie
}

\section{Experimental}

Test specimens were prepared from Cu37Zn (total impurities $<6000 \mathrm{ppm}$ ). The electrodes were embedded in epoxy resin in a Teflon holder and electrical contact achieved by means of a copper wire threaded into the base of the metal sample. The exposed surfaces were polished to a 1200 grit finish using SiC paper. They were then cleaned in distilled water and dried under a stream of air.

The electrochemical cell consisted of a three-electrode cell. A saturated calomel electrode (SCE) was used as the reference electrode, and high-density graphite rods were used as the auxiliary electrodes. All potentials quoted are on the SCE scale.

The electrolytes were prepared using analytical grade reagents and distilled water. The electropolymerization solution consisted of $0.1,0.2$, or $0.3 \mathrm{~mol} \mathrm{dm}^{-3}$ pyrrole added to a $0.125 \mathrm{~mol} \mathrm{dm}^{-3}$ sodium oxalate solution adjusted to a pH of 7.8. A $0.1 \mathrm{~mol} \mathrm{dm}^{-3} \mathrm{NaCl}$ solution, adjusted to $\mathrm{pH}$ values of 3.5 or 7.8 , using either $\mathrm{NaOH}$ or $\mathrm{HCl}$, was used as the aggressive solution.

Electrochemical experiments were carried out using an EG\&G PAR potentiostat, model 263. The electropolymerization was carried out at constant potentials varying from 800 to $1100 \mathrm{mV}$ (SCE). Once the polymers were formed the electrodes were rinsed with distilled water and then immersed in the chloride-containing solutions. Anodic polarization tests were performed by polarizing the electrodes from below the corrosion potential at a scan rate of $0.5 \mathrm{mV} \mathrm{s}^{-1}$ in the anodic direction. Cyclic voltammetry measurements were preformed in the monomer-free solutions at a scan rate of $20 \mathrm{mV} \mathrm{s}^{-1}$, or in $0.1 \mathrm{~mol} \mathrm{dm}^{-3} \mathrm{Na}_{2} \mathrm{SO}_{4}$ at $5 \mathrm{mV} \mathrm{s}^{-1}$. Scanning electron micrographs (SEMs) and energy dispersive X-ray (EDX) analyses were recorded on a Hitachi S-4700 cold cathode field emission SEM using a secondary electron detector and at an accelerating voltage of $15 \mathrm{kV}$. X-ray spectra were obtained using an Oxford Instruments Inca Energy EDX detector attached to the SEM. The samples were gold-coated prior to imaging using an Emitech K550 sputter coater. Fourier transform infrared (FTIR) spectra of the polymers were recorded between 500 and $4000 \mathrm{~cm}^{-1}$ using a Nicolet 400 D FT spectrometer. The spectra were obtained from compressed pellets of $\mathrm{KBr}$ in which powders of the polymer were evenly dispersed.

\section{Results}

The in situ electropolymerization of pyrrole at a $\mathrm{Cu}-\mathrm{Zn}$ electrode was attempted using two procedures, deposition by cycling the electrode in the monomer-containing solution and deposition by applying a constant potential to the electrode in the monomer-containing solution. The results obtained using these two methods are shown in Fig. 1 and 2, respectively. The data shown in Fig. 1 were recorded in a $0.2 \mathrm{~mol} \mathrm{dm}{ }^{-3}$ pyrrole solution by cycling the electrode between -500 and $1000 \mathrm{mV}$ (SCE). The voltammograms are characterized by a low current at potentials between -500 and $-150 \mathrm{mV}$ (SCE). However, as the potential is increased further, a sharp increase in the anodic current is observed, consistent with the onset of dissolution. 


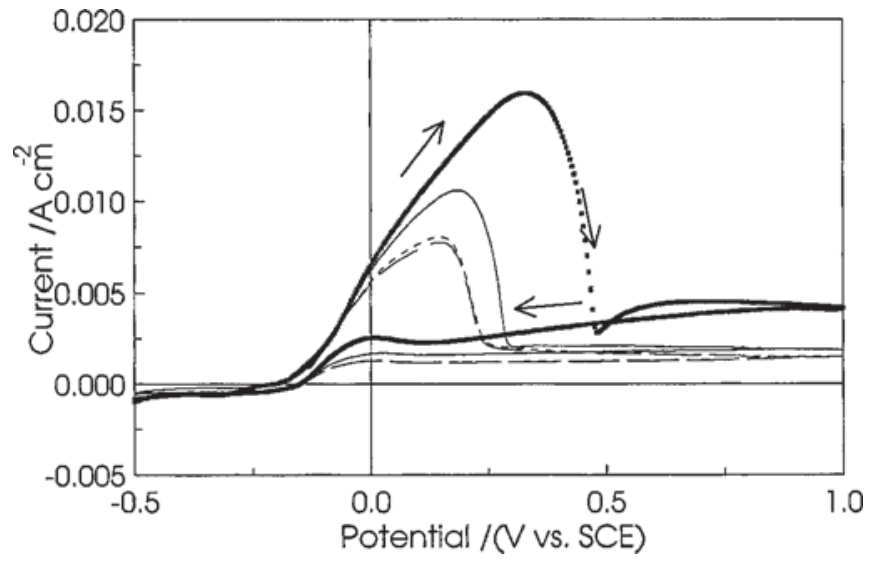

Figure 1. Cyclic voltammograms recorded for $\mathrm{CuZn}$ in a $0.2 \mathrm{~mol} \mathrm{\textrm {dm } ^ { - 3 }}$ pyrrole, $0.125 \mathrm{~mol} \mathrm{dm}^{-3} \mathrm{Na}_{2} \mathrm{C}_{2} \mathrm{O}_{4}$, pH 7.8 solution, ( • • •) 2nd cycle, (-) 4th cycle, (- - - 6th cycle, (--) 8th cycle.

A sharp decrease in the anodic current is observed at higher potentials as passivation, or pseudopassivation, of the CuZn electrode occurs. It is seen with successive cycles that the extent of the alloy dissolution event, or activation, is lowered and that the onset of passivation occurs at lower potentials. This procedure of alloy activation followed by alloy repassivation did not lead to the deposition of polypyrrole.

However, uniform adherent polypyrrole layers could be deposited at potentials in the pseudopassive domain. In these experiments, the pyrrole was electropolymerized directly at the CuZn electrode without any prior surface treatment or polarization step. Data showing the electropolymerization of pyrrole in a $0.2 \mathrm{~mol} \mathrm{dm}^{-3}$ pyrrolecontaining solution as a function of applied potential and at $900 \mathrm{mV}$ (SCE) as a function of the pyrrole concentration are shown in Fig. $2 \mathrm{a}$ and $\mathrm{b}$, respectively. Included also in Fig. $2 \mathrm{~b}$ are data recorded in the monomer-free solution at $900 \mathrm{mV}$ (SCE). It can be seen from these data that the current drops rapidly initially, but then increases to reach a peak value with subsequent decay at a much slower rate. This behavior can be seen more clearly in Fig. 2c, where the currenttime behavior on electropolymerization at $0.8 \mathrm{~V}$ (SCE) in a $0.2 \mathrm{~mol}$ $\mathrm{dm}^{-3}$ pyrrole solution is shown during the first $300 \mathrm{~s}$. In this case, the current drops rapidly during the first $9 \mathrm{~s}$ to reach a minimum value, the current then increases at a rate of $1.6 \times 10^{-4} \mathrm{~A} \mathrm{~s}^{-1}$ to reach a peak value at about $20 \mathrm{~s}$. This is followed by a somewhat slower, $6.5 \times 10^{-5} \mathrm{~A} \mathrm{~s}^{-1}$, decay in the current for approximately $20 \mathrm{~s}$, and then the current decays more slowly to reach the steadystate values shown in Fig. 2a and b. Although the magnitude of these peak currents, the time period at which they were observed, and the subsequent rates of decay varied somewhat with the applied potential and on the pyrrole concentration, they seem to be connected with the dissolution of the CuZn electrode in the oxalate solution and the formation of a complex oxalate surface. This is evident from the data recorded in the monomer-free solution, where a similar current-time profile can be seen. Further evidence to support this was obtained by depositing polypyrrole at an oxalate-modified CuZn electrode, as opposed to the direct approach used to record the data in Fig. 2. In these experiments, the CuZn electrode was polarized at $900 \mathrm{mV}$ (SCE) in the monomer-free oxalate solution and then pyrrole was added to the solution following a 30 min polarization period. On addition of pyrrole to the solution the current remained constant indicating that the initial oxidation current peaks, Fig. 2, are due to dissolution of the electrode and subsequent formation of a complex oxalate film as opposed to the nucleation of a polypyrrole film.

An interesting trend can be seen on comparing the near steadystate currents, that is the currents measured after approximately $1500 \mathrm{~s}$, Fig. 2a and b. High currents, typically $5 \mathrm{~mA} \mathrm{~cm}^{-2}$, are
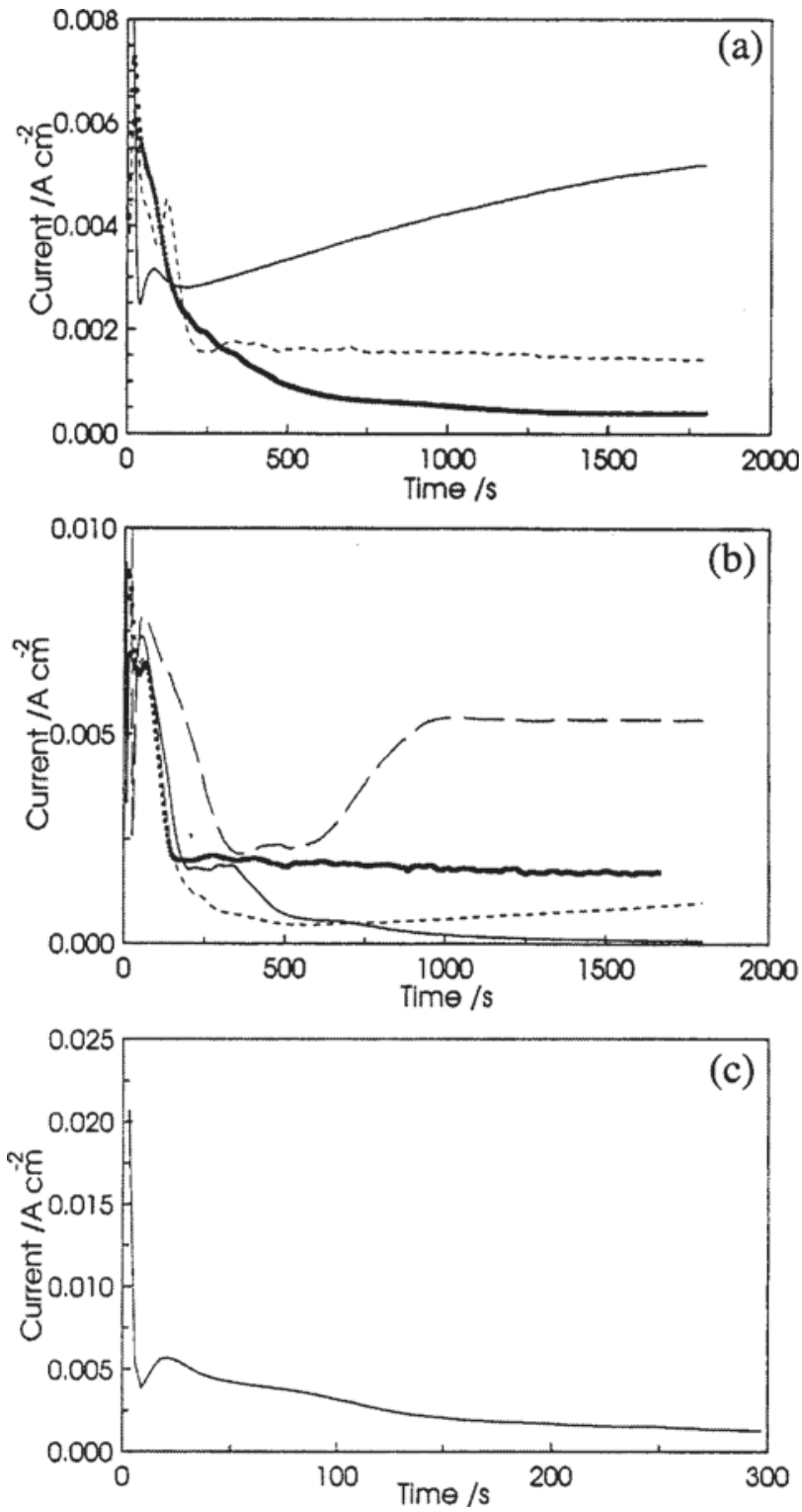

Figure 2. (a) Potentiostatic current-time plots for CuZn polarized in $0.2 \mathrm{~mol}$ $\mathrm{dm}^{-3}$ pyrrole in a $\mathrm{pH} 7.8,0.125 \mathrm{~mol} \mathrm{dm}^{-3} \mathrm{Na}_{2} \mathrm{C}_{2} \mathrm{O}_{4}$ at $(-) 1.1 \mathrm{~V}(\mathrm{SCE})$; (- - - ) $0.8 \mathrm{~V}(\mathrm{SCE})$; (一) $0.7 \mathrm{~V}(\mathrm{SCE})$. (b) Potentiostatic current-time plots for CuZn polarized at $0.9 \mathrm{~V}(\mathrm{SCE})$ in a pH $7.8,0.125 \mathrm{~mol} \mathrm{dm}^{-3}$ $\mathrm{Na}_{2} \mathrm{C}_{2} \mathrm{O}_{4}$ solution containing pyrrole concentrations of $(-) 0$, (-) 0.1 (--) 0.2 , and $(---) 0.3 \mathrm{~mol} \mathrm{dm}^{-3}$. (c) Potentiostatic current-time plots for

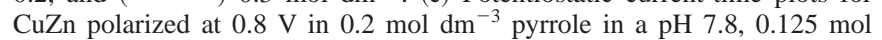
$\mathrm{dm}^{-3} \mathrm{Na}_{2} \mathrm{C}_{2} \mathrm{O}_{4}$ solution.

measured at the higher potentials, $1100 \mathrm{mV}$, and the higher pyrrole concentrations, $0.3 \mathrm{~mol} \mathrm{dm}{ }^{-3}$. These conditions favor higher rates of polypyrrole formation. However, the steady-state currents recorded in the monomer-free solution, $1.7 \mathrm{~mA} \mathrm{~cm}^{-2}$, are higher than those recorded in the solutions containing 0.1 or $0.2 \mathrm{~mol} \mathrm{dm}^{-3}$ pyrrole, Fig. 2b, conditions favoring a lower rate of polypyrrole formation. This appears to be connected with the fact that the activity of the CuZn electrode depends on the extent of electropolymerization. Under conditions that favor high rates of electropolymerization, the initial electropolymerized layer inhibits further dissolution of the electrode, whereas under conditions that favor low rates of electropolymerization, the CuZn electrode continues to oxidize and dissolve. It is also interesting to point out that these steady-state currents measured in the monomer-free solution indicate limited protective properties of the oxalate layers. 

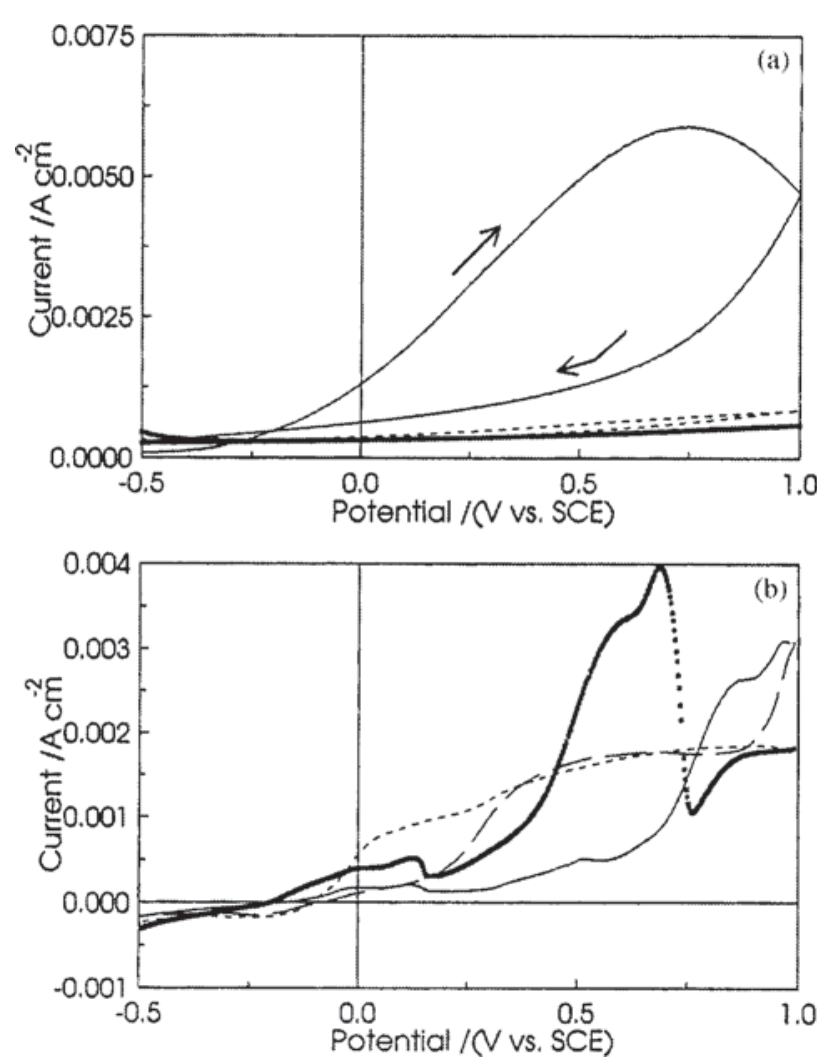

Figure 3. (a) Cyclic voltammograms recorded for pure zinc in a $0.125 \mathrm{~mol}$ $\mathrm{dm}^{-3} \mathrm{Na}_{2} \mathrm{C}_{2} \mathrm{O}_{4}$, pH 7.8 solution, (-) 1st cycle, $(---)$ 2nd cycle, and (-) 3rd cycle. (b) Cyclic voltammograms recorded for pure copper in a $0.125 \mathrm{~mol} \mathrm{dm}^{-3} \mathrm{Na}_{2} \mathrm{C}_{2} \mathrm{O}_{4}$, pH 7.8 solution, (*) 1 st cycle (forward scan), (--) 1st cycle (reverse scan), and (- - - 10th cycle (forward scan), and (-) 10th cycle (reverse scan).

In order to obtain more detailed information on the significance of the initial oxalate pseudopassive layer, experiments were carried out on the electrochemical behavior of pure $\mathrm{Zn}$ and pure $\mathrm{Cu}$ in this oxalate solution. Cyclic voltammograms showing the electrochemical activity of pure $\mathrm{Zn}$ and $\mathrm{Cu}$ cycled between the potential limits of -500 and $1000 \mathrm{mV}$ (SCE) in the monomer-free oxalate solution are shown in Fig. 3a and b, respectively. The electrochemical activity of $\mathrm{Zn}$ is very dependent on the cycle number. Dissolution of zinc can be seen clearly in the first cycle, with dissolution commencing at $-160 \mathrm{mV}$ (SCE) and increasing until potentials in the region of 750 $\mathrm{mV}$ (SCE) are reached. Dissolution can also be seen during the reverse scan. However much lower anodic currents are seen in the second and third cycles. This suggests the formation of a Zn-oxide or oxalate film during the first cycle that protects, to some extent, the zinc substrate. However, it was not possible to form polypyrrole at this zinc electrode, which suggests that the oxidized zinc layer is too insulating to enable formation of a polypyrrole film. The cyclic voltammograms recorded for pure $\mathrm{Cu}$, Figure $3 \mathrm{~b}$ show also that the electrochemical activity of pure $\mathrm{Cu}$ is dependent on the cycle number. Dissolution of copper begins at $-180 \mathrm{mV}$ (SCE), a peak is seen at $125 \mathrm{mV}$ (SCE) which is consistent with the formation of $\mathrm{Cu}(\mathrm{I})$ oxide. At higher potentials, $300 \mathrm{mV}$ (SCE), more intense dissolution is seen. It is unlikely under these conditions that the $\mathrm{Cu}(\mathrm{II})$ oxide is formed, or if it is formed, that it remains stable. The subsequent peaks at 580 and $680 \mathrm{mV}$ (SCE) appear to be connected with the formation of $\mathrm{Cu}(\mathrm{II})$ oxalates, with the likely oxalates being $\mathrm{Cu}(\mathrm{Ox})$ and $\mathrm{Cu}(\mathrm{Ox})_{2}^{2-}$, where Ox represents the oxalate species. The electrochemical activity is very different with repetitive cycling, as be seen by comparing the data recorded for the first and tenth cycles. The Cu(II) oxalate peaks are shifted to significantly higher poten- tials in the forward scan of the tenth cycle. The current remains high during the reverse cycle until the potential drops to about $200 \mathrm{mV}$ (SCE).

There are a number of reports in the literature which show that iron oxalate complexes can be transformed into iron oxides, for example, in a recent study by Nguyen et al., ${ }^{15}$ on the electrodeposition of polypyrrole coatings on an iron substrate, it is proposed that a three-dimensional iron oxide is formed due to the low solubility of the $\mathrm{Fe}(\mathrm{III})$ oxalate complex. However, there is very little evidence to support such an oxide-transformation step in these experiments. First, the $\mathrm{Cu}(\mathrm{II})$ oxalate complex species have a considerably lower solubility than either the iron(II) or iron(III) oxalates. The Fe(III) oxalate is known to be highly soluble, while the solubility of the $\mathrm{Fe}(\mathrm{II})$ oxalate is $1.5 \times 10^{-3} \mathrm{~mol} \mathrm{dm}^{-3}$, but the solubility of the $\mathrm{Cu}$ (II) oxalate is $1.5 \times 10^{-4} \mathrm{~mol} \mathrm{dm}^{-3}$; a significantly lower value. ${ }^{16}$ Accordingly, it is unlikely that this salt is sufficiently soluble to enable the formation of the corresponding oxide. Second, $\mathrm{Cu}(\mathrm{I})$ and $\mathrm{Cu}(\mathrm{II})$ oxides can be easily observed as reduction peaks in cyclic voltammetry, ${ }^{17}$ corresponding to the equilibria described in Eq. 1 and 2

$$
\begin{gathered}
2 \mathrm{Cu}(\mathrm{OH})_{2}+2 \mathrm{e}^{-} \rightarrow \mathrm{Cu}_{2} \mathrm{O}+2 \mathrm{OH}^{-}+\mathrm{H}_{2} \mathrm{O} \\
\mathrm{Cu}_{2} \mathrm{O}+2 \mathrm{H}^{+}+2 \mathrm{e}^{-} \rightarrow 2 \mathrm{Cu}+2 \mathrm{H}_{2} \mathrm{O}
\end{gathered}
$$

However, there was no evidence of such peaks in these experiments, even on polarizing the electrodes to reduction potentials in the region of $-1.0 \mathrm{~V}$ (SCE).

Although this system is complex, with the generation of $\mathrm{Cu}(\mathrm{II})$ oxalate species, it was possible to form polypyrrole at this copperoxalate layer, ${ }^{18}$ indicating that the copper-oxalate layer is sufficiently conducting to enable the polymerization of pyrrole at the interface, unlike that observed for pure $\mathrm{Zn}$.

In Fig. 4a an SEM micrograph of the polypyrrole film deposited on CuZn is shown. These polymers were formed in a $0.2 \mathrm{~mol} \mathrm{dm}^{-3}$ pyrrole solution at $900 \mathrm{mV}$ (SCE) and allowed to dehydrate over several days exposure to air at $25^{\circ} \mathrm{C}$. These data show clearly that the polymer is homogeneous and is crack and defect-free despite being dehydrated over an extended period, which indicates that the metal-polymer system is stable to ageing. The micrograph shows the characteristic microspheroidal grains or aggregates of polypyrrole, with sizes up to $5 \mu \mathrm{m}$. It is also interesting to note that the deposition of the polypyrrole appears to take place along polishing lines on the alloy surface, as evident from the ridge-like diagonal traces in the micrograph. The X-ray analysis of the area shown in Fig. 4a is provided in Fig. 4b. This shows the presence of carbon from the polypyrrole, but also copper and zinc. Although some of the copper and zinc signal obviously originates from the metal substrate, there also appears to be some copper and zinc trapped within the polymer. Evidence in support of this could be obtained by sampling different areas of the surface. In particular, the light-colored particles had higher copper and zinc counts suggesting higher concentrations of these species at such points. This suggests that copper and zinc oxalate species are present within the polymer structure.

The results of an FTIR analysis of the polypyrrole coating formed in a $0.2 \mathrm{~mol} \mathrm{dm}^{-3}$ pyrrole solution at $900 \mathrm{mV}$ (SCE) are presented in Table I. Here the wavenumber of the bands observed and the assignments of these bands, based on literature reports, ${ }^{19-21}$ are presented. Two important conclusions can be made. First, these bands are consistent with literature reports and can be assigned to polypyrrole. For example, the bands centered at $1088 \mathrm{~cm}^{-1}$ correspond to the $\mathrm{C}-\mathrm{H}$ and $\mathrm{N}-\mathrm{H}$ in-plane ring deformation, while the absorption at $802 \mathrm{~cm}^{-1}$ corresponds to the $\mathrm{C}-\mathrm{H}$ out-of-plane ring deformation. The characteristic C-C stretching vibration of the ring, centered at $1550 \mathrm{~cm}^{-1}$, is not seen due to the overlapping of this signal with the strong absorption at $1620 \mathrm{~cm}^{-1}$ of the oxalate counter anion. The position of this latter band was confirmed by recording the FTIR spectra of oxalate. Second, the presence of the doping oxalate can be clearly identified, showing, as expected, that these polymers are doped with oxalate anions. 


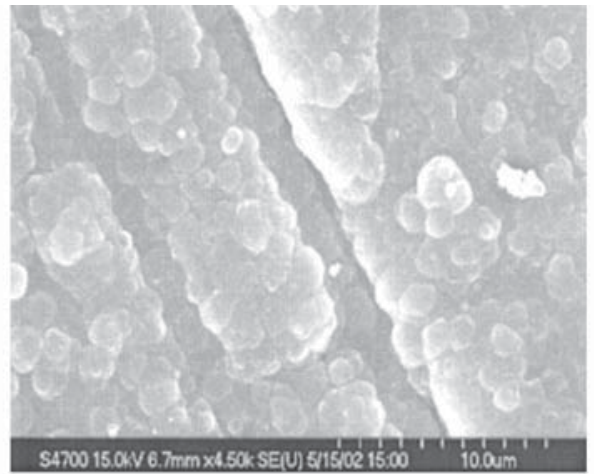

(a)

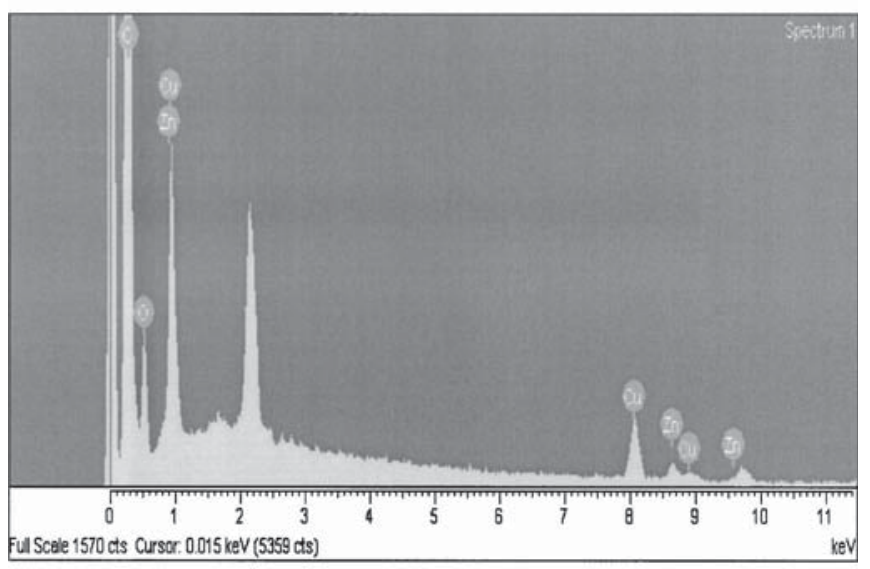

(b)

Figure 4. (a) SEM micrographs of the polypyrrole coated CuZn electrode. (b) X-ray analysis of the polypyrrole-coated electrode.

The data in Fig. 5a show the electrochemical behavior of the polypyrrole-coated CuZn electrode in $0.1 \mathrm{~mol} \mathrm{dm}{ }^{-3} \mathrm{Na}_{2} \mathrm{SO}_{4}$. Again, the polymer was deposited at $900 \mathrm{mV}$ (SCE) from a $0.2 \mathrm{~mol}$ $\mathrm{dm}^{-3}$ pyrrole solution. These data were recorded at a scan rate of 5 $\mathrm{mV} \mathrm{s}^{-1}$. Before cyclic polarization, the sample was polarized at 0.4 $\mathrm{V}$ (SCE) to enable oxidation of the polymer. These data are typical of pure polypyrrole cycled in a sulfate solution. ${ }^{22}$ Indeed similar data were recorded for polypyrrole deposited at pure platinum from a $1.0 \mathrm{~mol} \mathrm{dm}{ }^{-3} \mathrm{H}_{2} \mathrm{SO}_{4}$ solution. A reduction peak centered at -625 $\mathrm{mV}$ (SCE) and an oxidation peak at $-195 \mathrm{mV}$ (SCE) is observed, showing that the polypyrrole deposited at CuZn using the relatively high potential of $900 \mathrm{mV}$ (SCE) exhibits typical redox activity.

Similar data recorded for the uncoated CuZn electrode are presented in Fig. 5b. For the sake of comparison with the data presented in Fig. 1 these were recorded in the monomer-free solution. Low currents are measured at potentials between -500 and $-150 \mathrm{mV}$

Table I. FTIR analysis of polypyrrole deposited at $900 \mathrm{mV}$ (SCE) from a $0.2 \mathrm{~mol} \mathrm{dm}^{-3}$ pyrrole solution.

Wavenumber $\left(\mathrm{cm}^{-1}\right)$

\section{Assignment}

$1624(\mathrm{~s})(\mathrm{b})^{\mathrm{a}}$

1258 (s)

$1472(\mathrm{w})$

1088 (s)

1030 (s)

$802(\mathrm{~s})$

$680(\mathrm{w})$

\section{Oxalate counter anion}

$\mathrm{C}-\mathrm{O}$ stretch from oxalate counter anion $\mathrm{C}-\mathrm{N}$ stretching vibration of the ring

$\mathrm{C}-\mathrm{H}$ and $\mathrm{N}-\mathrm{H}$ in-plane deformation of ring

$\mathrm{C}-\mathrm{H}$ in-plane deformation of ring

$\mathrm{C}-\mathrm{H}$ out of plane ring deformation

C-C out-of-plane ring deformation or $\mathrm{C}-\mathrm{H}$ rocking

${ }^{\mathrm{a}} \mathrm{s}=$ strong, $\mathrm{b}=$ broad, $\mathrm{w}=$ weak.
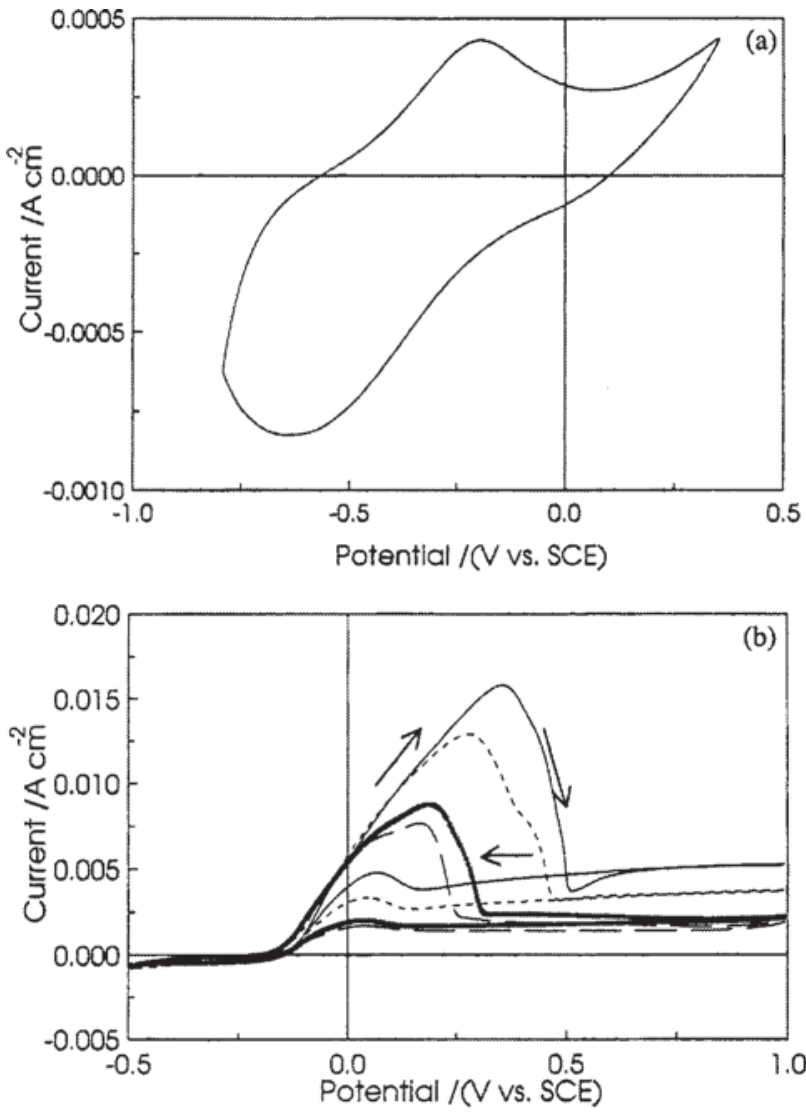

Figure 5. (a) Cyclic voltammograms recorded for polypyrrole-coated CuZn in a $0.1 \mathrm{~mol} \mathrm{dm}{ }^{-3} \mathrm{Na}_{2} \mathrm{SO}_{4}$ solution at a scan rate of $5 \mathrm{mV} \mathrm{s}^{-1}$. (b ) Cyclic voltammograms recorded for uncoated CuZn in 0.125 mol dm ${ }^{-3} \mathrm{Na}_{2} \mathrm{C}_{2} \mathrm{O}_{4}$, pH 7.8, (-) 2nd cycle, (--) 4th cycle, (-) 6th cycle, $(---)$ 8th cycle.

(SCE), but at potentials higher than $-100 \mathrm{mV}$ (SCE) an abrupt increase in the anodic current is observed indicating the activation and anodic dissolution of the electrode. At potentials higher than approximately $200 \mathrm{mV}$ (SCE) a rapid decrease in the anodic current is observed, consistent with the formation of a pseudopassive region. The electrodes appear to become more stable with successive cycling; the charge passed during the forward scan decreases with increasing cycle number. For example, the charges passed during the second, fourth, sixth, and eight cycles were typically $0.266,0.246$, 0.130 , and $0.102 \mathrm{C} \mathrm{cm}^{-2}$, respectively. It is interesting to point out that these voltammograms are similar to those presented in Fig. 1, which show that the electrochemical behavior of CuZn in the pyrrole-containing solution, under these cyclic conditions, is dominated by the electrochemical response of the CuZn-oxalate system. However, once the polymers are formed there is no evidence of any metal dissolution or repassivation, Fig. 5a. This indicates that the deposited polypyrrole coatings are stable and protective.

In order to assess the corrosion protection properties of the coated electrodes polarization plots were recorded for the coated and uncoated electrodes in the aggressive test solutions and compared. Representative plots showing the anodic polarization behavior of the coated and uncoated CuZn electrode in a $0.1 \mathrm{~mol} \mathrm{dm}^{-3} \mathrm{NaCl}$ solution adjusted to a pH of 3.5 and 7.8 are shown in Fig. 6a and b, respectively. For comparative purposes, the anodic polarization behavior of the oxalate-coated electrode in the acidified chloride solution is shown also in Fig. 6a. The anodic polarization behavior of CuZn and the oxalate-coated surface in the acidified solution is consistent with active dissolution. The anodic current increases steadily at potentials beyond the corrosion potential, which lies at $-130 \mathrm{mV}$ 

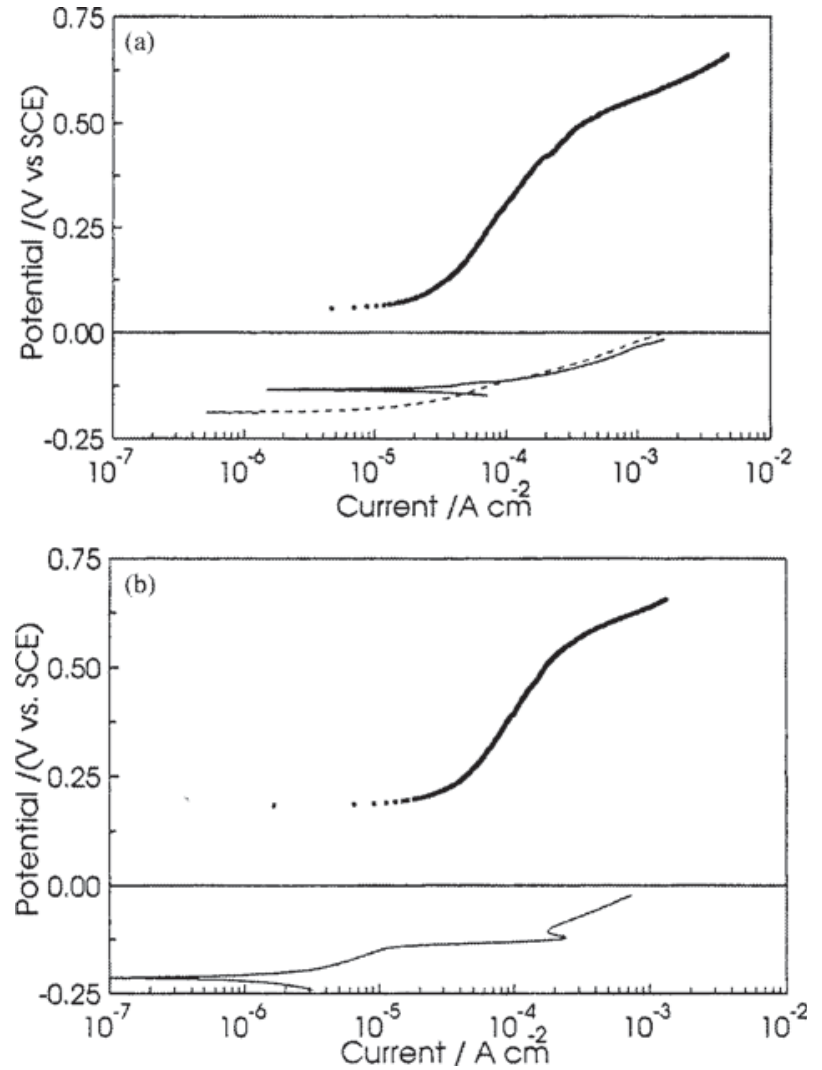

Figure 6. (a) Anodic polarization plots recorded in a $\mathrm{pH} 3.5,0.1 \mathrm{~mol} \mathrm{dm}^{-3}$ $\mathrm{NaCl}$ solution for $(\stackrel{-}{\longrightarrow}$ uncoated CuZn, $(\cdots)$ polypyrrole-coated CuZn, and $(---)$ oxalate-coated CuZn. (b) Anodic polarization plots recorded in a $\mathrm{pH} 7.8,0.1 \mathrm{~mol} \mathrm{dm}^{-3} \mathrm{NaCl}$ solution for $(-)$ uncoated $\mathrm{CuZn}$ and ( . . .) polypyrrole-coated CuZn.

(SCE) for the uncoated and $-190 \mathrm{mV}$ (SCE) for the oxalate-coated surface, to reach currents on the milliampere scale at approximately $-30 \mathrm{mV}$ (SCE). The polarization behavior of the polymer-coated CuZn electrode is significantly different, representing a much more corrosion-resistant system. The corrosion potential lies at a much more noble potential, $60 \mathrm{mV}$ (SCE), and the current recorded during polarization of the electrode to high anodic potentials remains low, increasing slightly with increasing potential, until potentials exceeding $500 \mathrm{mV}$ (SCE) are reached. A more rapid increase in the anodic current is observed at $520 \mathrm{mV}$ (SCE) indicating dissolution of the underlying substrate. Similar behavior is seen in the near-neutral solution; breakdown of the polymer-coated electrode does not occur until potentials exceeding $540 \mathrm{mV}$ (SCE) are reached. Dissolution of the substrate was confirmed by adding the indicator, Erichrome Black $\mathrm{T}$, to the test solution. This indicator, which is sensitive to the presence of zinc cations, changed color from its characteristic blue color to a pink-violet color, characteristic of the presence of $\mathrm{Zn}^{2+}$, at potentials just anodic to the breakdown potential. However, the copper-sensitive indicator, Murexide, did not undergo any color change at the breakdown potential indicating that these breakdown events involve, mainly, the dissolution of the zinc component. The currents recorded in the acidified solution are slightly higher than those recorded in the $\mathrm{pH} 7.8$, solution which may be connected to the conducting properties of the polypyrrole layer, being doped to a greater extent in the acidified solution. It is also important to point out that the oxalate coating offers no corrosion protection properties.

The open-circuit potential adopted by the uncoated and polymercoated CuZn electrode as a function of time in the $\mathrm{pH} 3.5$ and 7.8 chloride-containing solutions are shown in Fig. 7a and b respectively. The open-circuit potential of the uncoated electrodes reaches near-constant values after a short immersion period, approximately
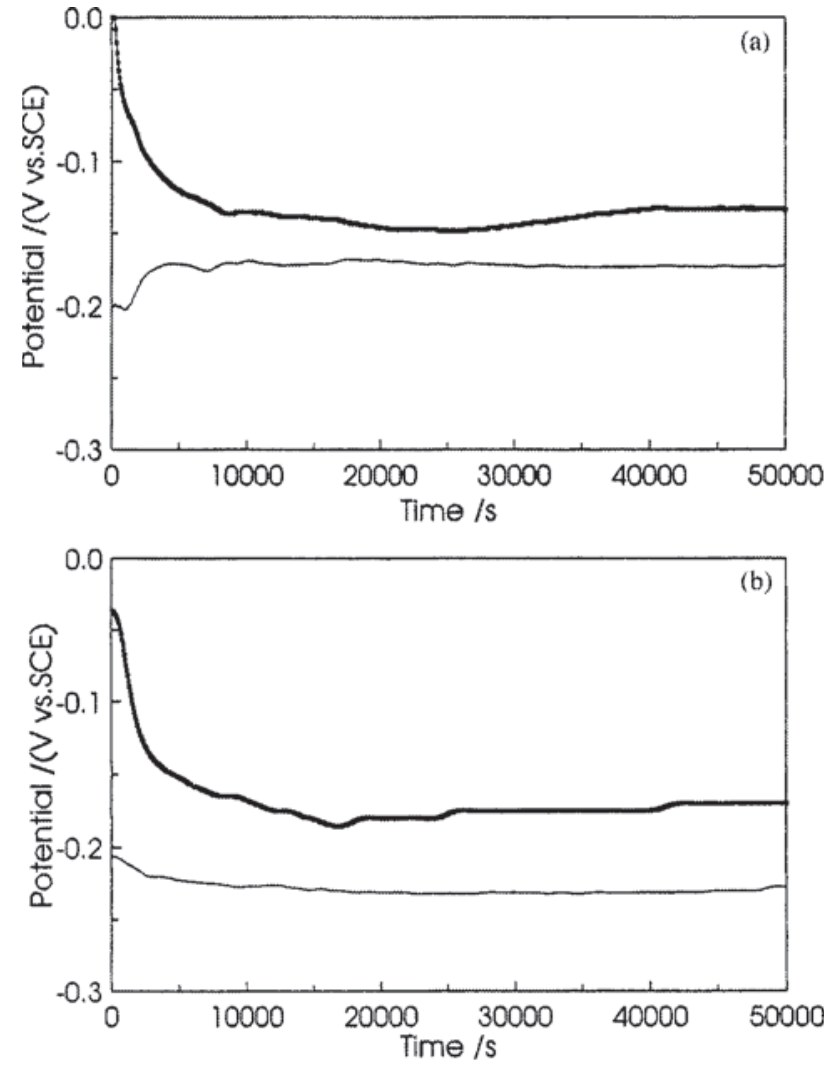

Figure 7. (a) Open-circuit potential-time plots recorded in a pH 3.5, $0.1 \mathrm{~mol}$ $\mathrm{dm}^{-3} \mathrm{NaCl}$ solution for $(-)$ uncoated $\mathrm{CuZn}$ and $(-)$ polypyrrolecoated CuZn. (b) Open-circuit potential-time plots recorded in a $\mathrm{pH}$ 7.8, 0.1 mol dm ${ }^{-3} \mathrm{NaCl}$ solution for $(-)$ uncoated CuZn and (-) polypyrrolecoated CuZn.

$6 \times 10^{3} \mathrm{~s}$. The open-circuit potential of the polymer-coated electrodes decays slowly and reaches near steady-state values after approximately $2 \times 10^{4} \mathrm{~s}$. At this point the differences between the open-circuit potentials of the coated and uncoated electrodes are approximately $60 \mathrm{mV}$ in the $\mathrm{pH} 7.8$ solution and approximately 34 $\mathrm{mV}$ in the $\mathrm{pH} 3.5$ solution. The anodic polarization behaviors of the coated and uncoated electrodes following the $14 \mathrm{~h}$ immersion period in the $\mathrm{pH} 7.8$ solution are shown in Fig. 8. Again, the more superior

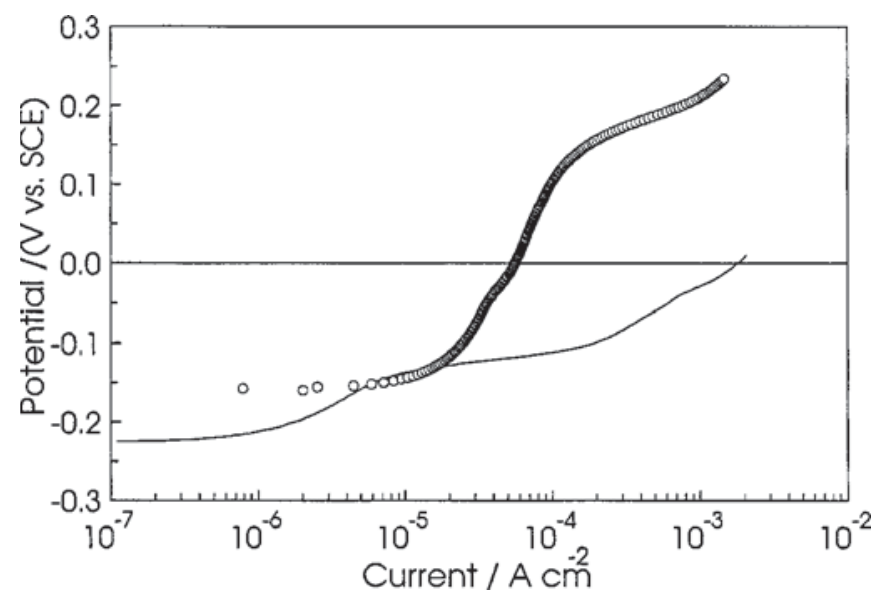

Figure 8. Anodic polarization plots recorded in a $\mathrm{pH} 7.8,0.1 \mathrm{~mol} \mathrm{dm}{ }^{-3}$ $\mathrm{NaCl}$ solution for $(-)$ uncoated $\mathrm{CuZn}$ and $(\cdot \cdot \cdot \cdot)$ polypyrrole-coated CuZn following a $14 \mathrm{~h}$ immersion period. 
corrosion resistance of the coated CuZn electrode can be seen here, with the difference between the breakdown potentials of the coated and uncoated electrodes, being of the order of $300 \mathrm{mV}$ (SCE). However, it can be seen on comparing these data to those presented in Fig. $6 \mathrm{~b}$ that the coated surface loses some of its corrosion protection properties on prolonged immersion in the halide solution.

\section{Discussion}

It can be seen from the results presented that adherent and homogeneous polypyrrole coatings can be deposited onto CuZn in the presence of oxalate anions at near-neutral $\mathrm{pH}$ values. These layers exhibit significant corrosion protection properties in highly aggressive chloride-containing solutions. The ease of formation of the polypyrrole layer at CuZn appears to be connected with the fact that a pseudopassive-like layer, or film, forms on the CuZn electrode under the electropolymerization conditions employed. This layer inhibits dissolution of the alloy and facilitates the formation of polypyrrole. It is interesting to note that these polypyrrole layers could not be formed at the CuZn electrode from other media, such as $\mathrm{HCl}$ or $\mathrm{H}_{2} \mathrm{SO}_{4}$. Similar effects have been reported for the deposition of conducting polyaniline on iron or steel. ${ }^{11-14}$ For example, the electrosynthesis of adherent polyaniline films on iron has been reported in oxalic and phosphoric acid media, but not in the presence of hydrochloric acid. This has been attributed to the formation of iron oxalate or iron phosphate layers on the metal surface, which are sufficiently protective to decrease the rate of iron dissolution but not sufficiently insulating to inhibit the electropolymerization process. Indeed, Bernard et al. ${ }^{11}$ have shown that the corrosion protection properties of the final polyaniline film is dependent on the nature of this passive layer.

This passive layer that forms in the neutral oxalate solution is complex, consisting of copper and zinc species. Morales et al. ${ }^{23,24}$ have shown, using XPS, that the passive layer formed on various brasses in a $\mathrm{pH} 9$ solution consists of a complex $\mathrm{ZnO} \cdot \mathrm{H}_{2} \mathrm{O} / \mathrm{Cu}_{2} \mathrm{O}-\mathrm{CuO}$ layer. The $\mathrm{ZnO}$ electroformation results in a dezincification process so that a thin copper-rich layer resides at the metal/oxide interface. The oxidation of zinc in this oxalate solution can be seen clearly from the first cycle in Fig. 3a, where the anodic current is seen to increase with increasing potential. However, on subsequent cycles, low anodic currents are measured being consistent with the precipitation of the oxalate complex, $\mathrm{ZnC}_{2} \mathrm{O}_{4}$, which is sparingly soluble with a $\mathrm{p} K_{\mathrm{s}}$ of $7.9^{25}$ (where $K_{\mathrm{s}}$ refers to the solubility product). Taking the oxalate concentration of 0.125 mol $\mathrm{dm}^{-3}$ and using the $\mathrm{p} K_{\mathrm{s}}$ value, it is seen that the solubility product is exceeded at a $\mathrm{Zn}^{2+}$ concentration of 1 $\times 10^{-7} \mathrm{~mol} \mathrm{dm}^{-3}$. However, the amount of $\mathrm{Zn}^{2+}$ calculated from the first cycle depicted in Fig. 3a is $1.5 \times 10^{-6} \mathrm{~mol}$, which shows that under these conditions the solubility product is exceeded at the surface, and accordingly $\mathrm{ZnC}_{2} \mathrm{O}_{4}$ is likely to form at the surface. The competing zinc oxide/hydroxide reaction may occur to some extent, but the $\mathrm{pH}$ of 7.8, is not sufficiently alkaline for this reaction to dominate the chemistry. Indeed, Macdonald et al. ${ }^{26}$ have concluded that the major zinc species at a $\mathrm{pH}$ of 7.8 are the soluble $\mathrm{Zn}^{2+}$ and $\mathrm{Zn}(\mathrm{OH})^{+}$species. The concentration of the passivating layer, $\mathrm{Zn}(\mathrm{OH})_{2}$, is essentially zero under these neutral $\mathrm{pH}$ conditions.

There is also clear evidence for the formation of copper oxalate complex species. For example, on comparing the data for pure zinc, pure copper, and copper-zinc, in Fig. 3a, b and 5b, it is clear that the data recorded for the copper-zinc electrode shows evidence of zinc oxidation and copper-oxalate complexation. In the case of the CuZn system, the anodic currents detected at low potentials, for example $-200 \mathrm{mV}$ (SCE) are consistent with the oxidation of zinc, whereas the anodic currents measured at the higher potentials, for example, 0.5 to $1.0 \mathrm{~V}$ (SCE) are similar to the second-cycle data recorded for the $\mathrm{Cu}$ system, indicating oxidation of the copper component and the formation of copper oxalate species. Evidence to support this idea of a mixed zinc and copper oxalate layer can be found from the fact that the electrochemical activity of the CuZn electrode is very different with successive cycling to that obtained for the pure $\mathrm{Zn}$ system, where a highly stable state is obtained on the second cycle. Also, the fact that pyrrole could not be electropolymerized at the zinc electrode is further proof for the presence of copper oxalate in the film formed on CuZn.

It is well known that oxalate anions form stable complexes with copper cations. In particular, oxalate anions $\left(\mathrm{Ox}^{2-}\right)$ form complexes with $\mathrm{Cu}^{2+}$ to generate copper oxalate complexes with a 1:1 and 1:2 stoichiometry.

$$
\begin{gathered}
\mathrm{Cu}^{2+}+\mathrm{Ox}^{2-} \rightleftharpoons \mathrm{Cu}(\mathrm{Ox}) \\
\mathrm{Cu}^{2+}+2 \mathrm{Ox}^{2-} \rightleftharpoons\left[\mathrm{Cu}(\mathrm{Ox})_{2}\right]^{2-}
\end{gathered}
$$

In addition, depending on the acidity of the medium, the 1:1 oxalate complex can be protonated in accordance with Eq. 5

$$
\mathrm{Cu}(\mathrm{Ox})+\mathrm{H}^{+} \rightleftharpoons[\mathrm{HCu}(\mathrm{Ox})]^{+}
$$

Zouaoui et al. ${ }^{27}$ have shown that $\left[\mathrm{Cu}(\mathrm{Ox})_{2}\right]^{2-}$ is the more stable complex in the $\mathrm{pH}$ range 3-11 for a solution of $\mathrm{Cu}^{2+}$ and $\mathrm{Ox}^{2-}$. Thus, the CuZn oxalate layer is likely to contain copper as the anionic $\left[\mathrm{Cu}(\mathrm{Ox})_{2}\right]^{2-}$ species. The inclusion of this complex in the initial layer is sufficient to reduce the insulating character of the pure zinc complex layer enabling the electropolymerization of pyrrole. There are also reports in the literature which show that the presence of dissolved $\mathrm{Cu}^{2+}$ species increases the polymer yield during the synthesis of conducting polymers, such as polypyrrole. ${ }^{28,29}$ For example, Miller et $a .^{28}$ in studying the reaction of pyrrole and thiophene monomers with copper- or nickel-exchanged mordenite found that polymerization occurred only with the copper-exchanged mordenite. This was attributed to the better oxidizing power of the $\mathrm{Cu}$ (II) cation. Thus, the presence of dissolved $\mathrm{Cu}^{2+}$ at the $\mathrm{CuZn}$ electrode may also be connected with the ease of electropolymerization at the CuZn electrode.

It can be seen from the data presented in Figs. 6, 7, and 8 that the polypyrrole-coated CuZn electrodes exhibit significant corrosion protection properties in both an acidified and neutral chloridecontaining solution, particularly following formation. There is a clear ennoblement in the open-circuit potentials, Fig. 7a and b, an effect that is also evident with polyaniline-coated iron electrodes, and which has been attributed generally to an anodic protection mechanism. ${ }^{13}$ It is interesting to compare the open-circuit potentialtime behavior of these polypyrrole-coated CuZn electrodes with those of polyaniline-coated iron. ${ }^{11}$ Both systems behave similarly during the early stages of immersion. The open-circuit potentials of both polymer-modified electrodes fall slowly until a near-steady state value is reached. However, in the case of the polyaniline-iron system the potential drops rapidly at some extended time, typically minutes to hours, to reach values near the open-circuit potential of the uncoated iron, signifying loss of the corrosion protection properties. This is not seen with the CuZn system; even after eight days of immersion, the potentials remain at the early steady-state values. Indeed, the ability of the polymer to protect the underlying alloy following $14 \mathrm{~h}$ immersion in a highly aggressive chloride solution can be seen clearly in Fig. 8. This apparent stability of the polypyrrole layer on the CuZn electrode may be connected to recent reports which show that $\mathrm{Cu}(\mathrm{I})$ can be used to enhance the conductivity and stability of polypyrrole. ${ }^{30}$ This has been attributed to electron transfer between copper and the $\mathrm{N}^{+}$of polypyrrole to form a stable $\mathrm{Cu}$-polypyrrole complex, thus preventing nucleophilic attack on the positively charged nitrogen, for example, by $\mathrm{H}_{2} \mathrm{O}$.

\section{Conclusions}

Pyrrole was successfully electropolymerized at a CuZn electrode in a near-neutral sodium oxalate solution to generate a homogeneous and adherent polypyrrole film. Dissolution of the CuZn electrode was inhibited through the formation of a pseudopassive layer comprising a zinc(II) and copper(II) oxalate species, at which the poly- 
pyrrole film nucleated. These films exhibited significant corrosion protection properties in acidified and neutral $0.1 \mathrm{~mol} \mathrm{dm}^{-3} \mathrm{NaCl}$ solutions.

\section{Acknowledgments}

The authors gratefully acknowledge the support of this work by Enterprise Ireland, under the Basic Science Research Grants Award, project code SC/99/106, and Wexford County Council. The authors also acknowledge the Biomedical Research Center at NUI Galway for carrying out the SEM/EDX measurements.

National University of Ireland Maynooth, assisted in meeting the publication costs of this article.

\section{References}

1. H. C. Shih and R. J. Tzou, J. Electrochem. Soc., 138, 958 (1991).

2. S. M. Sayed, E. A. Ashour, and B. G. Ateya, Corros. Sci., 36, 221 (1994).

3. D. Chadwick and T. Hashemi, Corros. Sci., 18, 39 (1978).

4. P. Gupta, R. S. Chaudhary, T. K. G. Namboodhiri, and B. Prakash, Br. Corros. J., London, 17, 136 (1982).

5. S. L. F. A. da Costa, S. M. L. Agostinho, and K. Nobe, J. Electrochem. Soc., 140, 3483 (1993).

6. A. M. Fenelon and C. B. Breslin, J. Appl. Electrochem., 31, 509 (2001).

7. M. A. Quraishi, I. H. Farooqi, and P. A. Saini, Br. Corros. J., London, 35, 78 (2000).

8. H. A. A. Elrahman, Corrosion (Houston), 47, 424 (1991).

9. S. K. Bag, S. B. Chakraborty, A. Roy, and S. R. Chaudhuri, Bull Electrochem, 13, 8 (1997).

10. S. K. Bag, S. B. Chakraborty, A. Roy, and S. R. Chaudhuri, Br. Corros. J., London, 31, 207 (1996).
11. M. C. Bernard, S. Joiret, A. Hugot-Le-Goff, and P. V. Phong, J. Electrochem. Soc., 148, B12 (2001)

12. J. L. Camalet, J. C. Lacroix, S. Aeiyach, K. Chane-Ching, and P. C. Lacaze, Synth Met., 93, 133 (1998)

13. G. M. Spinks, A. J. Dominis, G. G. Wallace, and D. E. Tallman, J. Solid State Chem., 6, 85 (2002).

14. M. C. Bernard, A. Hugot-Le Goff, S. Joiret, N. N. Dinh, and N. N. Toan, J. Electrochem. Soc., 146, 995 (1999).

15. H. N. Thi Le, B. Garcia, C. Deslouis, and Q. Le Xuan, Electrochim. Acta, 46, 4259 (2001).

16. CRC Handbook of Chemistry and Physics, 59th Ed., R. C. Weast, Editor, CRC Press Inc., Cleveland, OH (1979).

17. L. E. A. Berlouis, D. A. Maman, and I. G. Azpura, Surf. Sci., 408, 173 (1998).

18. A. M. Fenelon and C. B. Breslin, Electrochim. Acta, 47, 4467 (2002).

19. S. Wencheng and J. O. Iroh, Electrochim. Acta, 46, 1 (2000).

20. M. Omastove, M. Lazar, and S. Kosina, Polym. Int., 34, 151 (1994).

21. J. I. Martins, M. Bazzaoui, T. C. Reis, E. A. Bazzaoui, and L. Martins, Synth. Met. 129, 221 (2002).

22. J. Tamm, A. Halik, A. Alumaa, and V. Sammelselg, Electrochim. Acta, 42, 2929 (1997).

23. J. Morales, G. T. Fernandez, S. Gonzalez, P. Esparza, R. C. Salvarezza, and A. J. Arvia, Corros. Sci., 40, 177 (1998).

24. J. Morales, P. Esparza, G. T. Fernandez, G. Gonzalez, J. E. Garcia, J. Caceres, R. C. Salvarezza, and A. J. Arvia, Corros. Sci., 37, 231 (1995).

25. F. Berbel, J. Manuel Diaz-Cruz, C. Arino, and M. Esteban, J. Electroanal. Chem., 475, 99 (1999).

26. D. D. Macdonald, K. M. Ismail, and E. Sikora, J. Electrochem. Soc., 145, 9 (1998)

27. A. Zouaoui, O. Stephan, M. Carrier, and J.-C. Moutet, J. Electroanal. Chem., 474, 113 (1999).

28. G. J. Millar, G. F. McCann, C. M. Hobbis, G. A. Bowmaker, and R. P. Conney, J. Chem. Soc., Faraday Trans., 90, 2579 (1994).

29. B. L. Rivas and C. O. Sanchez, J. Appl. Polym. Sci., 82, 330 (2001).

30. Y.-C. Lie and B.-J. Hwang, J. Electroanal. Chem., 501, 100 (2001). 